\title{
EJIGABWÎN: A SILVICULTURA NA ENCRUZILHADA EM KITCISAKIK
}

\section{Marie Saint-Arnaud - Centro de Pesquisa em Educação e Formação Relativas ao Meio Ambiente e à Ecocidadania, Universidade do Quebec em Montreal}

\section{Charlie Papatie - Departamento Akî de Kitcisakik}

Na língua algonquina, Ejigabwîn se refere aos rastos deixados por um Anichinabél na encruzilhada das trilhas, ao caminhar na floresta. A palavra Ejigabwîn decorre da raiz Ej, a qual significa « pegada » (Cuoq 1886; Lemoine 1909) e encontra-se, por exemplo, em Ejicin para « deixar pegadas ». Por extensão, as pessoas de Kitcisakik2 usam Ejigabwîn para se referir a um momento decisivo, na encruzilhada das trilhas, quando se precisa fazer uma escolha: « Qual pegada deixaremos?» «Em qual direção seguimos?» Da mesma forma, é a palavra que os nossos colaboradores anichinabés escolheram para expressar a ideia de um « compromisso florestal », o qual começava a tomar forma a favor dos trabalhos de pesquisa que nós realizamos em Kitcisakik entre 2002 e 2010 (Saint-Arnaud 2009; Saint-Arnaud e al. 2005; Saint-Arnaud e al. 2009). Com efeito, eles associavam Ejigabwîn à nossa abordagem para identificar alternativas às práticas florestais industriais, as quais iam se intensificando sobre seu território ancestral em Abitibi-Témiscamingue (Quebec, Canadá).

Como acontece em muitas comunidades indígenas do Canadá, o território dos Anichinabés de Kitcisakik foi alvo de intervenções florestais contínuas desde o final do século XIX (Leroux e al. 2004; Leroux [a imprimir]; Vincent 1995). A degradação do meio ambiente dos Anichinabés fez com que eles se tornassem testemunhas impotentes e contribuiu em reforçar certo sentimento de alienação por parte deles. Essa degradação gerou uma grave crise social na comunidade. Para enfrentar esta problemática, os líderes de Kitcisakik, sob o incentivo do seu chefe James Papatie, se envolveram num processo de pesquisa participativa, em conjunto com uma equipe universitária e um agrupamento de parceiros industriais e governamentais. Esta iniciativa permitiu dar início a um diálogo intercultural com o objetivo de definir os fundamentos de uma silvicultura dita "indígena”. Esta última se adequaria melhor aos valores, ao modo de vida e às aspirações da população de Kitcisakik.

Neste artigo, apresentamos o sistema anichinabé das representações da floresta e da silvicultura da forma como o descobrimos através dos nossos trabalhos. Em segundo lugar, relatamos como surgiu a ideia de um « compromisso florestal » em Kitcisakik através da estruturação de um conjunto de princípios e critérios de silvicultura indígena. Veremos em que medida esses resultados de pesquisa poderão tomar forma no contexto da implementação da nova Lei quebequense sobre o ordenamento sustentável do território florestal (L.R.Q., c.A-18.1) e da evolução das exigências da certificação florestal.

\section{CONTEXTO}

A comunidade de Kitcisakik conta com quatrocentos e trinta membros que vivem no coração da floresta boreal 
meridional em uma parte do seu território ancestral, situado principalmente no Refúgio de vida selvagem nacional La Vérendrye, o qual ocupa hoje em dia uma superfície de aproximadamente $6000 \mathrm{~km} 2$. A comunidade fica a uma centena de quilômetros ao sul de Val-d'Or na região do Abitibi-Témiscamingue (fig. 1) e seus membros vivem em condições precárias. Eles já foram qualificados como « semissedentários », dividindo seus deslocamentos entre um local histórico de reunião de verão às margens do Grand lac Victoria (foto 1), um acampamento rústico localizado no terreno familiar usado para a caça realizada com o uso de armadilhas e habitações rudimentares construídas na beira do reservatório Dozois onde se encontram certos serviços (escola, creche, guincho/lanchonete, posto de gasolina, posto de saúde, centro comunitário e escritórios administrativos). Para esta comunidade, os processos referentes à educação, à saúde, ao emprego e à moradia constituem parte dos desafios para o futuro. O projeto de construção de Wanaki, o novo vilarejo, representa tanto uma esperança quanto uma grande mudança uma vez que ele poderia significar a relocação da comunidade (sobre este tema, ver o número de Recherches amérindiennes au Québec, XLI (2-3), 2011).

A degradação do meio ambiente decorrendo da silvicultura industrial constitui outro grande desafio para a população de Kitcisakik. Com efeito, mais de $60 \%$ dos povoamentos florestais do seu território foram recolhidos desde a época da mecanização das operações florestais no começo da década de 1970. O meio ambiente e o modo de vida dos indígenas foi então radicalmente transformado. Em 2002, na hora de empreender este projeto de pesquisa, uma dezena de empresas tinham contratos de abastecimento e de ordenamento florestal (CAAF) em longo prazo neste território. Todo ano, se recolhiam aproximadamente $400000 \mathrm{~m} 3$ de madeira, ou seja, o equivalente a 10000 carregamentos de caminhões em um território percorrido por mais de $4500 \mathrm{~km}$ de caminhos florestais. Apesar de tal mudança, a comunidade de Kitcisakik manteve uma ligação muito forte com o seu território e o seu modo de vida tradicional. As atividades de subsistência não são mais o principal apoio alimentar dos Algonquinos, porém elas conservam uma grande importância cultural (Bousquet, 2002). A pesca do sander vitreus e do esturjão, a caça do alce e as atividades de caça realizada com o uso de armadilhas continuam suscitando grande interesse e constituem os fundamentos da cultura anichinabé.

No decorrer do inverno de 1998, as frustrações da população diante da indústria florestal se intensificaram. Isso levou ao bloqueio de estradas e criou grandes tensões sociais na região: as estratégias de ordenamento florestal3 não consideravam a presença indígena, a paisagem estava danificada pela colheita florestal, o modo de vida da população de Kitcisakik estava afetado, os processos de consulta eram inadequados, a linguagem florestal era complexa e o material cartográfico usado para as consultas dava uma representação confusa e parcial das operações florestais. A comunidade de Kitcisakik estava consideravelmente desfalcada de capacidade para enfrentar os desafios da silvicultura. Além disso, as relações de poder entre a indústria, o governo e as comunidades locais estavam amplamente desequilibradas (Croteau [a publicar]).

Ao sair da crise de 1998, o chefe James Papatie resumia a situação da seguinte forma: «Naquela época, eu percebia que a comunidade não podia entender a linguagem florestal. Tambémnãotínhamos a possibilidade de entender o que estava acontecendo». Por esse motivo, ao sermos convidados para participar do Conselho dos Anicinapek de Kitcisakik, elaboramos este projeto de pesquisa colaborativa em parceria com oito empresas florestais 4 e com o apoio 
da unidade de gestão regional do Ministério dos Recursos Naturais5.

Entre 2002 e 2010, o contexto legislativo e econômico das operações florestais no Quebec e no Canadá evoluiu de forma significativa, influindo até certo ponto na realização da pesquisa. Assim, em 2004, duas sentenças do Supremo Tribunal do Canadá (Taku River e Haïda Nation) confirmaram o dever da Coroa de consultar e ir ao encontro das necessidades dos povos indígenas para qualquer projeto de desenvolvimento que poderia prejudicar os seus direitos ancestrais ou legados de tratados. As Primeiras Nações do Quebec nunca aprovaram o processo de consulta desenvolvido a seguir pelo governo do Quebec (GTICA 2008). Por seu lado, o Instituto de desenvolvimento sustentável das Primeiras Nações do Quebec-Labrador (IDDPNQL 2005) propunha um protocolo próprio, o qual não foi aprovado pelos organismos governamentais. A consulta dos povos indígenas na questão de ordenamento florestal se tornou um desafio crucial.

Além disso, a partir da metade da década de 2000, devido à crise florestal, a qual causou o encerramento de várias fábricas, a colheita da madeira na região sofreu uma queda drástica. Mas para a população de Kitcisakik, as preocupações relativas à silvicultura permanecem hoje em dia. Com efeito, desde abril de 2013, o retrato do Quebec florestal não é mais o mesmo: a nova Lei sobre o ordenamento sustentável do território florestal modifica completamente o sistema de gestão das florestas. As principais mudanças abrangem a descentralização do planejamento do ordenamento florestal pela implementação de tabelas regionais de controle integrado dos recursos e do território (TGIRT), a adoção generalizada de estratégias de ordenamento ecosistêmico6 e a implementação de um programa de « florestas de proximidade », um tipo de delegação comunitária da administração de certos territórios florestais. Tais mudanças têm repercussões importantes sobre os indígenas considerando que maioria das 42 comunidades indígenas do Quebec estão estabelecidas na floresta.

Por outro lado, em março de 2013, o governo voltou atrás na sua decisão de se responsabilizar pela certificação florestal7, em particular devido às incertezas sobre a conformidade do Ministério dos Recursos Naturais do Quebec quanto aos critérios do Forest Stewardship Council (FSC) sobre o respeito dos direitos dos povos indígenas e do principio do consentimento livre, prévio e informado (CLPI). Efetivamente, sob a influência do mercado de consumidores de madeira e de papel, a certificação florestal se torna uma prerrogativa das operações industriais em qualquer lugar do mundo. Os sistemas de certificação florestal, particularmente os padrões desenvolvidos pelo FSC, propõem um quadro de avaliação voluntário do ordenamento florestal, o qual exerce geralmente mais restrições do que as legislações nacionais. De fato, se as Primeiras Nações consideram geralmente que a certificação florestal demora para dar os resultados esperados em matéria de reconhecimento dos seus direitos e de recaídas ligadas à economia florestal (IDDPNQL 2013), os novos critérios adotados pelo FSC International em março de 2012 e as novas diretivas quanto ao consentimento livre, prévio e informado dos povos indígenas (FSC 2012) poderiam mudar as regras do jogo.

\section{MARCO TEÓRICO E METODOLÓGICO}

O marco conceitual da « silvicultura indígena » no Canadá se constituiu gradualmente a partir da metade da 
década de 1990. Identificado inicialmente a partir de uma série de práticas que caracterizavam o compromisso das Primeiras Nações com o ordenamento florestal, por exemplo, com a criação da Associação Nacional de Silvicultura Autóctone (ANFA) em 1989, o conceito daquilo que cabe chamar de « silvicultura indígena » foi definido aos poucos graças a várias pesquisas realizadas em todas as províncias e territórios do Canadá com a colaboração de muitas nações indígenas (Brubacher 1998; Davidson-Hunt 2003; Natcher 2008; Parsons et Prest 2003; Sherry e al. 2005; Wyatt 2008). Além disso, o Acordo da Paz dos Bravos entre o Governo do Quebec e os Crees da Baía de James (Governo do Quebec 2002), é um exemplo frequentemente citado. Com efeito, ele proporia um modelo de silvicultura vantajoso para as Primeiras Nações (Conselho dos Crees-Quebec sobre a silvicultura 2009). Da mesma forma, o projeto de Floresta modelo das comunidades indígenas crees de Waswanipi, no território da Baía de James, foi durante dez anos um local de experimentação em silvicultura indígena (Waswanipi Cree Model Forest 2007).

Desde a adoção do Processo de Montreal em 1992, as práticas de ordenamento florestal sustentável se desenvolveram em todo lugar do mundo considerando as abordagens avaliativas por critérios e indicadores. Assim, o Canadá foi o líder neste assunto. Ao longo dos quinze últimos anos, certas nações indígenas no Canadá tentaram adaptar os quadros de critérios e indicadores existentes a nível nacional (CCMF 2006) à sua especificidade cultural (Lévesque e al. 1997; Gladu e Watkinson 2004; Programa canadense de florestas modelos 2000). Outros elaboraram seus próprios critérios e indicadores de ordenamento florestal sustentável se referindo a uma abordagem ancorada nos valores comunitários. Por exemplo, é o caso dos Crees de Little Red River em Alberta (Natcher e Hickey 2002) e dos Tl'azt'ens da Colúmbia-Britânica (Karjala e al. 2003; Karjala e al. 2004; Sherry e al. 2005). Os quadros desenvolvidos por epara as comunidades seriam efetivamente mais pertinentes para dar expressão aos conhecimentos locais, às práticas e às crenças, e também para avaliar o ordenamento florestal ligado à cultura, o uso do território e o desenvolvimento comunitário. De acordo com Sherry e al. (2005), uma pertinência maior também se traduziria por mais interesse e mais motivação por parte das comunidades locais em se envolver nos assuntos florestais. Os diferentes sistemas de certificação florestal vigentes em todo lugar do mundo se baseiam também em abordagens de acordo com critérios e indicadores para determinar o desempenho das organizações.

Apesar das abordagens por critérios e indicadores incluírem um nível de complexidade podendo constituir um obstáculo ao seu uso (Collier e al. 2002), escolhemos este tipo de abordagem, porque permitia constituir uma ferramenta de planejamento estratégico e uma tabela de análise global ancorada nos valores comunitários dos Anichinabés.

O projeto se articulava ao redor de várias dimensões para as quais identificamos objetivos científicos e de desenvolvimento comunitário. A dimensão participativa e educativa, a qual era transversal ao conjunto da nossa pesquisa, baseava-se sobre um quadro de referência em educação relativa ao meio ambiente(Sauvé 1997, 2005; Sauvé eal. 2005). A estratégia da comunidade de aprendizagem (Gayford 2003; Orellana 2005; Davidson-Hunt e O'Flaherty 2007) permitiu estabelecer um verdadeiro diálogo de conhecimentos e de experiências entre os pesquisadores e os nossos parceiros governamentais e industriais, assim como dentro da própria comunidade.

A dimensão etnográfica procurava caracterizar a relação Anichinabés/floresta/silvicultura. Adotamos uma 
abordagem fenomenológica (Marton 1994; Merriam 1998) que se baseava sobre a experiência e a visão do mundo dos membros da comunidade de Kitcisakik. O quadro teórico das representações sociais (Sauvé e Garnier 2000; Jodelet 2003) nos pareceu particularmente pertinente para entender melhor as bases da relação com a floresta dos Anichinabés de Kitcisakik e clarificar os diferentes lados da problemática florestal vivenciada pela comunidade. Ao abordar os sistemas de interpretação das relações dos humanos entre eles e com o seu meio ambiente, o estudo das representações sociais permitia entender a relação Anichinabés/floresta/silvicultura em uma perspectiva cultural, sistêmica e holística. Nós nos baseamos então nas dimensões cognitivas, afetivas, valorais e comportamentais da sua experiência.

Nossa equipe escolheu uma metodologia multi-estratégica adaptativa (Smith 1999) para levantar os dados da pesquisa. Entre março de 2003 e abril de 2007, encontramos 33 pessoas no âmbito de 17 entrevistas semiestruturadas realizadas em um contexto individual ou familiar. As numerosas atividades que organizamos, ou das quais participamos integrando um questionamento de pesquisa, permitiram levantar os comentários de 42 pessoas adicionais. Essas atividades de coleta de dados chamadas « adaptativas » se desenvolveram através de projetos fotográficos, expedições de canoa, balcões de informações, jogos de bingo florestal, atelier com os idosos e saídas no campo. No total, recolhemos os testemunhos de 79 membros da comunidade, o que representa 34 \% da população adulta de Kitcisakik.

A análise do material de pesquisa (mais de 400 páginas de transcrição de entrevistas e anotações de campo) foi feita de acordo com os métodos clássicos de análise de conteúdo e de categorização dos dados qualitativos (Bardin 1993). Este trabalho permitiu elaborar uma « cartografia » do sistema anichinabé de representações da floresta e da silvicultura. Nós adotamos uma abordagem substantiva para « nomear » um elemento representacional. Assim, associamos as palavras « floresta » e « silvicultura » à outra palavra, a qual ilustrava de forma sintética ideia principal de cada elemento (por exemplo: « floresta-medicina », « silvicultura-deserto »). Com a colaboração dos nossos assistentes anichinabés, realizamos também uma análise lexicológica detalhada e uma pesquisa sobre os conceitos e o vocabulário algonquino (Saint-Arnaud 2009). A pesquisa contribuiu em enriquecer a nossa descrição com palavras algonquinas que caracterizavam bem melhor do que em francês a natureza dos elementos representacionais estudados.

Nós desenvolvemos a dimensão estratégica da pesquisa com um processo de teorização ancorada (Merriam 1998). Um conjunto de critérios de ordenamento florestal indígena foi induzido a partir dos elementos da representação anichinabé da floresta e da silvicultura. Numa segunda fase, elaboramos a estrutura do quadro agrupando os critérios em cinco princípios de ordenamento florestal. Nós iniciamos uma fase de identificação dos indicadores que deverá ser completada pela comunidade e os seus parceiros. Os critérios de silvicultura anichinabé foram discutidos e validados no âmbito de um atelier de uma duração de dois dias, o qual aconteceu na Floresta de ensino e de pesquisa do lago Duparquet (UQAM/UQAT) [foto 3]. Nove membros da comunidade de faixas etárias diferentes participaram. Nós trabalhamos a partir de três conjuntos de pequenos mapas fotográficos. Esses mapas ilustravam os elementos da paisagem local e envolviam membros da comunidade. No verso, os mapas incluíam textos que permitiam validar os elementos de representação da floresta e da silvicultura e os critérios de silvicultura indígena, os quais nós tínhamos destacado. O quadro de princípios e critérios foi comentado e validado por quatro informantes-chave. A validação foi completada de acordo com um processo de triangulação entre os membros da nossa equipe interdisciplinare os nossos 
parceiros industriais e governamentais.

\section{ELEMENTOS ETIMOLÓGICOS E SEMÂNTICOS}

Nopimik, «Ali, do outro lado do rio »

Na língua algonquina, a palavra « floresta » não se traduz literalmente. Lemoine (1909) relata a expressão endaje mitikokak que significa: « o lugar onde há árvores », mitik, significando « árvore ». É por isso que as pessoas de Kitcisakik, ao iniciarmos nossos trabalhos, tinham dificuldade em traduzir « floresta » em algonquino. A palavra mais comumente usada pelos Anichinabés é nopimik (Dumont e Papatie-Dumont 1985), palavra que esses últimos traduzem por « no bosque ». Os dicionários antigos definem nopiming (Cuoq 1886 ; Lemoine 1909) por « no bosque », « no território de caça » ou « do lado oposto à margem da água, se afastando do rio ». Para os Anichinabés que os primeiros missionários-linguistas encontraram, nopimik era então associado à « Hinterlândia ». De fato, ao se deslocar principalmente sobre a água, esses últimos percebiam a floresta como se correspondesse ao espaço no « interior das terras ». Aliás, os Innus, os quais frequentavam as costas do rio Saint-Laurent e do Atlântico, designavam os membros das outras nações mais florestais como sendo « aqueles do interior das terras » (Cuoq 1886). De acordo com outras línguas da família algonquina, Drapeau (1999) nota que « floresta » na língua innu se traduz por nutshimit. Os Attikameks usam notcimik (Wyatt 2004) e os Crees, a palavra nahamiic (Tanner 2007) para se referir ao « bosque » ou, the bush na língua inglesa.

Da mesma forma usada pelos Inuit para descrever a neve, existe uma série de palavras que representam diferentes tipos de florestas. Essas últimas se diferenciam pelas espécies de árvores pelas quais são compostas, pelo tipo de habitat natural ao qual são associadas ou por certas qualidades quanto a sua cor, a sua densidade ou a sua facilidade de acesso e deslocamento pelos indígenas. Assim, nomearemos mitikwa a floresta densa e escura, a qual abriga a marta, e que se associa às velhas florestas resinosas. Minokwa significa « bela floresta ». É nessa última que o Anichinabé pode se deslocar facilmente para praticar, por exemplo, as suas atividades de caça realizada com o uso de armadilhas. Ela é constituída de grandes árvores maduras. Nota-se também uma denominação utilitarista do espaço arborizado pela associação com diferentes ações ou atividades exercidas pelos Anichinabés. Desta forma, fala-se em algonquino: ir para o bosque (tcekatik), cortar madeira (kickatik), o sufixo tik sendo derivado de mitik para « árvore »; o sufixo kwa também é usado como, por exemplo, na palavra minokwa.

\section{NOPIMIK, A FLORESTA IDENTITÁRIA}

A análise do sistema representacional dos Anichinabés destaca o caráter identitário da relação que eles mantêm com a floresta. Nota-se que a floresta é incontestavelmente ligada ao território anichinabé na perspectiva multidimensional de uma « paisagem cultural », segundo a expressão usada por Parcs Canada (Buggey 1999) e pela UNESCO (2013). Da mesma forma daquilo que acontece para muitos povos indígenas espalhados pelo mundo, o território ecológico e o território cultural constituem os fundamentos de um sistema socio-ecológico dinâmico no 
qual a transmissão dos conhecimentos ligados ao meio ambiente natural desempenha um papel determinante para a manutenção da identidade (Berkes e Folke 1998; Davidson-Hunt e Berkes 2003).

Questionados sobre o sentido que davamà palavra « floresta », os participantes da nossa pesquisa responderam frequentemente: Ati eji otisinan, «É de onde eu sou ». Com o uso da palavra eji, notamos mais uma vez a ideia de pegadas nesta resposta em algonquino: « a floresta, é onde se encontram as minhas pegadas ». Aliás, Wyatt (2004, 2006) recebia uma resposta similar ao pesquisar com os Attikameks de Wemotaci, confirmando assim a dimensão identitária da floresta para outras nações da etnia algonquina.

Descrevemos o sistema representacional da floresta dos Anichinabés de Kitcisakik por uma constelação de elementos, os quais, apesar de não ser mutuamente exclusivos, podem se classificar em duas categorias:

1) Akî ou a « floresta-ambiente de vida » corresponde ao território ecológico. Akî é o apoio biofísico que permite a expressão cultural. Trata-se do « espaço de interação de todos os seres vivos », aquilo a que se refere sem dúvida mais precisamente a nossa ideia de natureza, meio ambiente ou ecossistema.

2) Anicinape madiziwîn, a « floresta-modo de vida », descreve o território cultural. De acordo com Cuoq (1886), a partícula atisi significa « ter uma forma de viver e de se comportar ». Madiziwîn é a palavra que mais tem a ver com a ideia de cultura para a qual os dicionários antigos não providenciam equivalência.

Os Anichinabés consideram a floresta como um todo, cujos elementos culturais e biofísicos são indissociáveis. Esses elementos traduzem esta visão do mundo holístico, a qual é característica das culturas indígenas das Américas. Desta forma, cabe lembrar que somente propomos uma categorização artificial. De fato, de acordo com os nossos informantes, « tudo é importante, tudo está vinculado ». Porém, um dia, um idoso respondeu, enquanto mostrava um espaço de meio centímetro entre polegar e indicador: « o importante, são os pequenos brotos dos quais a perdiz se alimenta ». Do menor ao maior, notamos uma representação sistêmica dos diferentes componentes deste « espaço de interação entre todos os seres vivos ». Não estaríamos perto de uma definição científica dos conceitos de ecossistemas e de biodiversidade? Com efeito, os Anichinabés são um povo da floresta boreal meridional, a qual é uma floresta com vários tipos de árvores. Este ecossistema, dominado pela mistura das essências resinosas e latifoliadas, influenciou o desenvolvimento da cultura dos Anichinabés e sua representação da floresta. Assim, a diversidade de espécies de árvores resulta sendo uma característica importante do seu ambiente de vida e daquilo que chamam minokwa, uma « bela floresta ».

O nosso esforço de categorização permitiu observar que o campo representacional da floresta para os Anichinabés inclui um núcleo importante. Esseúltimo parece não termudado desde a época colonial e todas as gerações o compartilham. Hoje em dia ainda se observam nele as principais referências culturais e cosmogônicas, as quais traduzem uma relação tradicional com a floresta (Leroux 2003; Tanner 1979; Savard 2004). Isso é evidenciado sem dúvida na história das pessoas de Kitcisakik, mas também na sua condição atual, a qual é ainda fortemente vinculada à 
vida na floresta.

Identificamos sete elementos de representação que constituem o território ecológico ou a « floresta-ambiente de vida». Primeiro, os Anichinabés associaram regularmente a floresta com a « Mãe Terra8 » ou Djôjô Akî. Na verdade, tratar-se-ia de um neologismo indígena, frequentemente usado no discurso das Primeiras Nações para qualificar a sua relação com a terra genitora, protetora e nutridora. Ela acolhe e apoia qualquer forma de vida. Além disso, encontra-se também uma equivalência bastante comum dentro das culturas andinas da Bolívia e do Peru através do conceito da Pacha Mama, o qual significa « Mãe Terra » na língua quíchua.

A « floresta-ambiente de vida » inclui um conjunto de outros elementos intervinculados: a « floresta-mundo dos espíritos », a « floresta-território anichinabé » e a « floresta-casa dos animais ». Representa-se a floresta sendo um espaço que abriga e nutre qualquer forma de vida: os espíritos, os animais e os Anichinabés em si próprios. Identificamos também um conjunto de elementos essenciais à sobrevivência e à segurança dos Anichinabés, os quais constituem as dimensões alimentar (a « floresta-despensa»), terapêutica (a « floresta-medicina ») e material (a « floresta -utilidade»).

O segundo agrupamento se refere ao território cultural dos Anichinabés: a « floresta-modo de vida » ou o Anicinape madiziwin: Trata-se do lugar de expressão da cultura anichinabé. Este subconjunto inclui a « florestaherança », (« o que se deixa aos filhos »), a « floresta-responsabilidade » (« nós somos os guardiões da floresta »), a « floresta-vida comunitária e familiar », espaço de coesão social e de transmissão da cultura (a « floresta-ensino »). A « floresta-atividades de subsistência » é o lugar no qual o Anichinabé expressa a sua competência cultural ligada à sobrevivência. De fato, as pessoas de Kitcisakik expressaram frequentemente, usando esta forma, a sua ligação com o ambiente florestal: « se não tiver floresta, não tem Anichinabé », comprovando assim um vinculo orgânico, espiritual e material entre floresta e sobrevivência, nas suas dimensões tanto culturais quanto biológicas.

\section{KAGI ONACTCIKADEKAKÎ, A FLORESTA COLONIZADA}

Contudo, um fenômeno contemporâneo modificou radicalmente o sistema representacional da floresta dos Anichinabés: a silvicultura. Com efeito, para o povo de Kitcisakik, a floresta é então alterada pelas operações florestais industriais. A maioria dos elementos mencionados anteriormente testemunha uma representação da floresta ligada à vida tradicional anichinabé e traduz uma referência identitária profunda que teria permanecido relativamente estável desde o período pré-colonial. Entretanto, a floresta é também associada à colonização de Anicinape Akî, a Terra indígena. As nossas entrevistas mostraram que as pessoas de Kitcisakik não podem mais se referir à floresta sem associar um conjunto de elementos negativos decorrendo da silvicultura industrial. Neste contexto, a ligação que os Anichinabés fazem entre a floresta de hoje e de amanhã está carregada de incerteza (a « floresta-porvir? »).

A « floresta colonizada » é uma dimensão determinante do sistema contemporâneo de representação da floresta para o povo de Kitcisakik. A análise da evolução da língua algonquina através da forma pela qual ela integrou conceitos novos é reveladora. Assim, não existe nenhuma palavra nesta língua para « colonizado ». Questionado sobre 
este assunto, Jimmy Papatie propõe a seguinte expressão: kagi onactcikadek Akî, a qual significa literalmente « no passado (kagi), a Terra (Akî) foi destruída (onactcikadek) ». Esta expressão traduz a associação estabelecida pelos Anichinabés entre a destruição do meio ambiente e a colonização. Que se trate da construção das estradas, da realização de usinas hidrelétricas ou das atividades florestais industriais, " a Terra foi destruída ». Neste aspecto, a análise do Relato das invasões realizado por Leroux (1992) testemunha de forma clara esta representação do território e da floresta colonizada tal como lhe contou Manie Michel, uma idosa da comunidade hoje falecida.

Os nossos dados sobre a « floresta colonizada» permitiram estabelecer duas categorias, as quais representam de certa forma o preto e o branco de uma mesma representação: de um lado, « a bela floresta de antigamente » ou minokwa weckatc na língua algonquina, expressão que traduz a nostalgia dos Anichinabés através a ideia da « floresta perdida». De outro lado, a « floresta devastada», que eles nomearam manaden, representa o seu ambiente de vida, feio, doente e poluído pelas atividades industriais.

\section{KICKATIKWENINÎ, A SILVICULTURA PREOCUPANTE}

Os Anichinabés traduzem a palavra silvicultura por kîckatikweninî, ou seja, « aqueles que cortam » as árvores. É desta forma que os seus ancestrais identificavam os primeiros lenhadores encontrados na metade do século XIX. Hoje em dia, as pessoas de Kitcisakik usam esta mesma expressão para se referir aos trabalhadores florestais, à indústria florestal ou à silvicultura.

Os elementos do sistema representacional que caracterizam a relação dos Anichinabés de Kitcisakik com a silvicultura traduzem um conjunto de preocupações, de sentimentos de frustração, de raiva e de pena. De acordo com as pessoas de todas as gerações encontradas ao longo da nossa pesquisa, a silvicultura é associada à degradação de Akî eà perturbação do modo de vida Anichinabé.

Nailustração da figura 3, encontramos um conjunto de elementos ligados ao território ecológico: a «silviculturadestruição dos habitats da vida selvagem » e a « silvicultura-desaparecimento da caça »; as « florestas sintéticas » (por causa dos métodos inadequados de reflorestamento), o « deserto », consequência do corte raso; a « silviculturacaminhos florestais » que fragmenta o território e modifica as condições de acessibilidade; a « silvicultura-desorientação » que leva à perda de referências no campo; a « silvicultura-poluição e doenças » dos homens, dos animais e de Akî; e a « silvicultura-catástrofes naturais » que contribui para as mudanças climáticas.

Para expressar a perturbação do seu modo de vida, os membros da comunidade testemunham um conjunto de elementos representacionais ligados à usurpação do território e ao sentimento de alienação causado. Por último, outro agrupamento associa-se à falta de respeito. Vários membros da comunidade mencionaram a desonra quanto à espoliação do território. De acordo com os Anichinabés, as atividades florestais criam conflitos, têm por consequência a mentira, causam desperdício e incomodam os espíritos da floresta. Finalmente, os kickatikweninî são associados aos « ouvidos moucos ». Ao qualificar as consultas, eles denunciam: « eles não nos ouvem »! 
Este retrato da silvicultura é dominado por elementos fortemente negativos e preocupantes. Porém, ao longo dos oito anos durante os quais o projeto foi desenvolvido, e a favor das numerosas atividades de pesquisa que permitiram estabelecer um diálogo comunitário ao redor dos assuntos florestais, assistimos à emergência de uma nova representação da silvicultura. Nessa última, os Anichinabés retomam certa forma de controle sobre o seu meio ambiente e, finalmente, sobre a sua própria vida. É isso que os membros do Comitê Floresta chamaram Ejigabwîn, expressão que traduzimos por « silvicultura-compromisso ». Esta categoria emergente permite descobrir uma modificação da relação com a floresta e com a silvicultura. Ela se inscreve na contemporaneidade e abre a via do desenvolvimento de uma silvicultura indígena em Kitcisakik.

\section{EJIGABWINN, A IDEIA DE UM COMPROMISSO FLORESTAL}

É verdade que a própria ideia de um compromisso resulta do sentimento generalizado de impotência e de resignação que expressaram as pessoas de Kitcisakik: « silvicultura-alienação », « silvicultura-usurpação ». Contudo, a interação entre certos outros elementos representacionais ligados à floresta mostram diversas falhas cometidas pela silvicultura. Diante do inevitável destino (a « floresta-perdida ») e a prioridade para preparar um futuro melhor para a juventude indígena (a « floresta-porvir? »), as pessoas de Kitcisakik se questionam sobre os seus valores tradicionais vinculados ao seu dever de proteger a floresta (a « floresta-responsabilidade », a « floresta-herança »).

Este depoimento de um jovem pai de família de Kitcisakik demonstra certa mudança do discurso quanto à silvicultura:

Às vezes, é preciso se arriscar. Se não conseguimos nada, não receberemos nada. Vai precisar de compromissos para conseguir alguma coisa. Mesmo se a silvicultura traz coisas negativas, ela também traz o positivo. [...] Há assuntos que vão ter que ficar bem.

À medida que evoluía a ideia de « silvicultura-compromisso », o Comitê Floresta de Kitcisakik, responsável pelo território e pelos recursos naturais, estabelecido de forma permanente após os nossos trabalhos, passou a investir cada vez mais no reforço das capacidades comunitárias e o desenvolvimento de ferramentas estratégicas: inventários multi-recursos, mapa de afetação do território, mapa de potencial dos lugares de interesses (Germain e Asselin 2011), códigos de práticas para proteger as espécies selvagens vulneráveis, modelização de roteiros florestais (Larouche 2008), base de dados sobre plantas medicinais, pesquisas sobre os conhecimentos tradicionais ligados com o ordenamento florestal (Uprety e al. 2013), etc.

Pode-se dizer que a nossa abordagem de pesquisa, articulada ao redor da definição de silvicultura indígena, corria risco pelo fato de impor novos pensamentos a serviço do desenvolvimento. Será que éramos cúmplices de um processo de controle cultural (Bonfil Batalla 1989; Rioja Ballivian 2005), de alienação ou de imposição de elementos desconhecidos à cultura dos Anichinabés? Será que esta pesquisa exploratória não contribuiu para a emergência de uma representação da silvicultura que não existia na cultura tradicional? Sim, mas o paradigma crítico (Robottom e 
Sauvé 2003) e a abordagem dialógica, os quais caracterizam a estratégia da comunidade de aprendizagem adotada pela nossa equipe, permitiram enfrentar este desafio ético enfatizando a investigação crítica dos assuntos florestais e das relações de poder envolvidas na repartição do acesso aos recursos.

Assim, identificamos sete elementos derepresentação queaspessoas de Kitcisakikassociaramaumasilvicultura mais compatível com sua visão do mundo e com suas aspirações: a « silvicultura-alternativas de ordenamento », a 《 silvicultura-empregos/parcerias », a « silvicultura-conservação/restauração », a « silvicultura-compensação », a « silvicultura-educação », a « silvicultura-participação/consulta » e a « silvicultura-respeito da cultura anichinabé ». Esses elementos representacionais permitiram estruturar um quadro anichinabé de princípios e de critérios, os quais constituem os fundamentos de uma silvicultura indígena em Kitcisakik.

\section{OS CINCO PRINCÍPIOS E OS 22 CRITÉRIOS DE SILVICULTURA ANICHINABÉ}

Os nossos trabalhos permitiram identificar cinco princípios de silvicultura anichinabé que constituem de certa forma as linhas diretrizes do « compromisso florestal » para o povo de Kitcisakik (ver figura 4). Trata-se dos princípios cultural (Anicinape madiziwîn), ético (Inakonigewîn), ecológico (Akî), educativo (Kikinôhamâgewîn) e econômico (Conia). Esses cinco princípios se sustentam de acordo com 22 critérios que especificam as características sócio-ecológicas de uma silvicultura aceitável para o povo de Kitcisakik. Esses critérios foram identificados, discutidos e validados ao longo de ateliers comunitários (ver foto 3). Os princípios são complementares e certos critérios são de natureza transversal (respeito dos direitos ancestrais, consulta adaptada, controle local das decisões, valorização dos conhecimentos).

O princípio cultural - Anicinape madiziwîn

« Se eu vivesse na cidade, eu me sentiria igual a um índio desenraizado. »

\section{(Uma Anichinabé)}

O princípio cultural de silvicultura anichinabé tem por objetivo a proteção e o desenvolvimento da cultura das pessoas de Kitcisakik pela valorização da floresta. Para os Anichinabés, a floresta é associada a um conjunto de elementos da cultura tradicional, o qual testemunha o seu modo de vida ainda fortemente enraizado no ambiente florestal. O princípio cultural propõe as condições que permitem substituir a representação negativa da « silviculturaperturbação do modo de vida » e da « silvicultura-falta de respeito ». Este princípio de ordenamento florestal poderá se expressar somente em relação aos princípios educativos e éticos, por exemplo, através do respeito dos valores anichinabés (critério 2.2) e da valorização dos conhecimentos locais (critério 4.2).

O princípio cultural se define através de quatro critérios, os quais especificam as condições de uma silvicultura aceitável: 1.1) a realização das atividades de subsistência e outras atividades culturais; 1.2) a proteção e a restauração dos lugares de interesse cultural; 1.3) a acessibilidade ao território ancestral e aos seus recursos; 1.4) a proteção e a restauração da qualidade visual das paisagens e das referências sobre o território. 
O princípio ético - Inakonigewîn

«A exploração florestal vai continuar. O dever dos Anicinapek será proteger a floresta. »

(Uma idosa de Kitcisakik)

O princípio ético é único no quadro de silvicultura de Kitcisakik. Ele tem como principal objetivo a participação comunitária do ordenamento florestal respeitando os fundamentos da cultura anichinabé. Ele é composto de sete critérios que se referem ao respeito dos direitos, dos valores e da organização social e territorial dos Anichinabés. Este princípio, traduzido por inakonigewîn pelos nossos assistentes de pesquisa, se apoia sobre as regras sociais anichinabés. $\mathrm{Na}$ língua algonquina, inakonige significa « costumes ». Esta palavra se usa para se referir a uma forma de deontologia indígena nas Américas (por exemplo, para se referir ao « contrato social » adotado pela comunidade). O princípio ético encontra seus fundamentos na cultura tradicional que se articulou e se manteve ao redor da representação da « floresta-responsabilidade ». Neste aspecto, Poirier (2000) se referiu ao « modo de compromisso » dos indígenas quanto ao território, expressão traduzida na língua algonquina por « cuidar » (Oganakinetenâwa, de Ogana, « cuidar », e kinet, « nós »). Ao ser atualizado no contexto do ordenamento florestal, o princípio ético propõe uma resposta para a representação da « silvicultura-desperdício » e da « silvicultura-poluição/doença ».

Conforme a jurisprudência canadense e os quadros de silvicultura indígena desenvolvidos por outras nações indígenas das Américas, a proposta de Kitcisakik se articula ao redor do respeito dos direitos ancestrais e da participação dos indígenas da gestão florestal. Os critérios 2.6 e 2.7 exigem a realização de consultas adaptadas e o controle local das decisões sobre o ordenamento do território e o acesso aos recursos, duas reivindicações recorrentes das Primeiras Nações.

Neste aspecto, sabemos que a nova Lei sobre o ordenamento sustentável do território florestal vigente no Quebec desde abril de 2013 não corresponde de forma satisfatória aos critérios estabelecidos por Kitcisakik. É verdade que o artigo 6 considera « interesses, valores e necessidades » das comunidades indígenas, mas ele não reconhece formalmente os seus direitos ancestrais, como mencionado na Constituição canadense (1982, art. 35).

Por outro lado, os artigos 7 e 8 da Lei reiteram a obrigação da Coroa de consultar as Primeiras Nações e a possibilidade de fechar acordos particulares com elas. Neste contexto, o governo já implementou mesas de conciliação regional nas quais todos os atores participam juntos da avaliação dos planos de ordenamento florestal. Embora o governo não tenha excluído a realização de um processo específico para os povos indígenas, isto provoca confusão e também não respeita, desde o início, o seu direito de consulta distinta permitindo a sua participação do planejamento estratégico. Neste aspecto, a comunidade de Kitcisakik não tem nenhuma certeza de que o critério 2.6 do quadro anichinabé seja respeitado.

Por último, o controle local das decisões pelas pessoas de Kitcisakik na questão do ordenamento florestal e do acesso aos recursos (critério 2.7) também faz parte das reivindicações tradicionais dos indígenas do Canadá, os quais 
reclamam a autonomia governamental e a cogestão dos recursos naturais. Neste aspecto, o princípio do consentimento prévio, livre e esclarecido (CPLI), inscrito na Declaração sobre os direitos dos povos indígenas (ONU 2007), o qual gera um grande consenso em direito internacional (Lebuis e King-Ruel 2010), recebe o apoio limitado dos governos canadense e quebequense. Por outro lado, o princípio indígena do FSC exige que os titulares de um certificado obtenham o acordo dos povos indígenas para as operações florestais sobre os seus territórios. Contudo, Teitelbaum e Wyatt (2012) avaliaram que foram sinalizadas não conformidades aos indicadores do princípio indígena para 86\% dos 21 certificados atribuídos ao Quebec e a Ontário no dia 31 de março de 2011. O desafio relativo ao consentimento dos povos indígenas (indicador 3.1.2 da norma boreal) gerava não conformidades do requerente em mais de $70 \%$ dos casos. Além disso, os novos princípios e critérios adotados pelo FSC em março de 2012 reforçam as exigências da certificação, particularmente quanto ao consentimento dos indígenas (FSC 2012). Isso gera muitas preocupações de acordo com as futuras condições necessárias para assegurar a manutenção dos certificados no Quebec.

O princípio ecológico - Akî

«O que mais me preocupa, são os animais. Eles não têm mais para onde ir. Em cada terreno de família, deveria ter uma despensa.»

(Uma mulher de Kitcisakik)

O objetivo deste princípio de silvicultura indígena é assegurar a integridade biológica dos ecossistemas de Kitcisakik Akî, o território ancestral dos Anichinabés. Os quatro critérios foram induzidos a partir dos elementos do sistema representacional da « floresta-ambiente de vida ». Adam e Kneeshaw (2008) mostraram que nos quadros de silvicultura indígena, os critérios e indicadores ecológicos incluíam uma dimensão cultural. Com efeito, o princípio ecológico é vinculado a vários elementos da representação da « floresta-ambiente de vida anichinabé ».

Por causa da intensidade dos cortes florestais que aconteceram no território de Kitcisakik desde a década de 1970, a restauração é um tema transversal que envolve vários critérios. Notaremos também que a representação da « silvicultura-alternativa de ordenamento » é onipresente através do princípio ecológico. De forma geral, é verdade que os Anichinabés associam a colheita de matéria lenhosa, realizada segundo o método clássico de corte total, à « silvicultura-deserto ». Eles consideram que o corte florestal praticado desde as últimas quatro décadas não se adéqua à proteção da biodiversidade nem ao respeito da relação que eles mantêm com a floresta. Eles privilegiam os cortes com preservação do coberto florestal por razões ecológicas, estéticas e vinculadas ao seu modo de ocupação do território. Os trabalhos de Larouche (2008) em Kitcisakik e de Germain (2012) com os Algonquins de Pikogan mostraram que as estratégias ecossistêmicas eram mais sujeitas a responder aos critérios indígenas do que os roteiros clássicos de corte total. Aliás, a silvicultura no Quebec evolui neste sentido por razões ligadas à proteção da biodiversidade e à manutenção dos atributos naturais das florestas. Contudo, os indígenas não enxergam nenhuma garantia nessas práticas de que os seus territórios e o acesso aos recursos sejam mais bem protegidos. A diversidade de definições e de estratégias que se associa ao ordenamento ecossistêmico não é alheia a certa desconfiança que persiste. Em Kitcisakik, 
por exemplo, existe certa desconfiança diante dessas abordagens promovidas pela nova gestão florestal.

O princípio educativo - Kikinôhamâgewîn

«Quando você faz uma pergunta a um idoso, ele nunca te dará a resposta diretamente: ele vai te contar uma lenda. A resposta, você mesmo tem que achá-la. Se você quiser aprender, você tem que sair para o bosque. »

(Um jovem pai de família anichinabé)

O princípio educativo é uma característica específica do quadro de silvicultura anichinabé. Ele traduz a importância que o povo de Kitcisakik atribui à educação. Este princípio tem uma dimensão intercultural dado que ele tem como objetivo a promoção das aprendizagens adaptativas e colaborativas entre os atores. Ele inclui dois critérios que abrangem a valorização dos conhecimentos indígenas e o reforço das capacidades locais.

Para os Anichinabés, como para a maioria das nações autóctones, a floresta é uma escola, um local de aprendizagem experiencial e de intercâmbio com os idosos, um ambiente privilegiado de contato com a tradição (Cajete 1994; Davidson-Hunt 2003; Sauvé e al. 2005; Berkes e Davidson-Hunt 2006). Isto é, na língua algonquina, « educação » se traduz por kinomage. A partícula kino significa « imitar ». Isso evidencia também a importância do acompanhamento dos idosos na aprendizagem da sobrevivência e na transmissão dos elementos culturais.

Em 1995, a Associação nacional para a silvicultura indígena tinha insistido sobre o papel essencial da educação para a sobrevivência cultural propondo ao Conselho canadense dos ministros das florestas (CCMF) adotarem um indicador sobre as aprendizagens colaborativas (mutual learning). O CCMF não assumiu esta proposta e incentivou então as Primeiras Nações a desenvolverem os seus próprios quadros locais de critérios e indicadores.

Oprincípio educativoécapital no processo de transformação social, o qual supõea realização de uma silvicultura 
indígena em Kitcisakik. Este percurso poderá ser emancipador na medida em que ele permitirá aos Anichinabés modificarem sua representação da « silvicultura-alienação ». Os jovens de Kitcisakik são sensíveis a esta transformação e já se envolveram na valorização da sua cultura através de criações cinematográficas, musicais ou televisuais nas quais eles transmitem de forma nova sua representação da « floresta identitária » e da « floresta colonizada »9.

Além disso, no contexto da realização do ordenamento ecossistêmico previsto pela reforma da gestão florestal quebequense, os conhecimentos indígenas sobre as características pré-industriais da floresta e seus conhecimentos das condições florestais naturais, baseadas sobre observações transmitidas de geração em geração, poderiam contribuir de forma vantajosa.

O princípio econômico - Conia

«Hoje, as empresas estão aqui. Vamos precisar de compromissos. A comunidade tem que estabelecer parcerias. Agora, a gente tem projetos e pesquisas também. É isso que vai nos ajudar a criar empregos na comunidade. »

\section{(Um jovem de Kitcisakik)}

Embora eles tenham traduzido este princípio por conia, que significa « dinheiro », os participantes do nosso estudo insistiram sobre o fato de que a silvicultura indígena devia priorizar o desenvolvimento comunitário e a melhoria da sua qualidade de vida. Os cinco critérios do princípio econômico são baseados na valorização da floresta além da simples colheita da matéria lenhosa. O povo de Kitcisakik tem a impressão de ter perdido « a bela floresta de antigamente ». Assim, a ideia de uma « silvicultura-compensação » é um elemento importante da silvicultura indígena. O critério 5.1 sobre a divisão justa das repercussões econômicas da exploração florestal se inscreve nesta perspectiva.

As parcerias econômicas (critério 5.2) e a criação de empregos (critério 5.3) permanecem as principais vantagens que o povo de Kitcisakik associa à silvicultura indígena. Elas constituem também uma exigência da certificação florestal FSC. Contudo, da mesma forma que Natcher (2006) levantou o problema para os Crees de Little Red River em Alberta, notamos que poucas pessoas entre os Anichinabés, incluindo os jovens, são capazes de se projetar em um emprego na área da indústria florestal. A maioria percebe o desenvolvimento econômico da sua comunidade através das atividades de valorização como o turismo, a exploração dos produtos florestais não lenhosos ou a construção de casas. O critério 5.4 que supõe a manutenção e a valorização das atividades de subsistência constitui também um elemento identitário a considerar para o desenvolvimento de uma nova economia florestal.

\section{RUMO À IMPLEMENTAÇÃO DA SILVICULTURA INDÍGENA}

Apesar dos investimentos importantes para o desenvolvimento de propostas muito estruturadas de princípios e critérios de silvicultura indígena no Canadá, vários fatores limitaram sua realização. Stevenson e Perreault (2008) mostraram que era necessário ultrapassar o diagnóstico tradicional do « déficit das capacidades » para entender melhor aquilo que não funciona com a participação efetiva das nações autóctones no desenvolvimento de sua economia 
florestal. Esses autores insistem sobre a importância da aquisição de competências coletivas, tanto nas comunidades quanto nas organizações governamentais e industriais. Fraser e al. (2006) mostraram que a problemática ligada à disponibilidade dos dados faz com que a estratégia por critérios e indicadores corra risco de perder a sua pertinência. Em outro caso estudado pelos autores, o processo de participação comunitária tinha demorado tanto que os resultados tinham sido obtidos tarde demais para ser aplicáveis.

Em Kitcisakik, os primeiros esforços permitindo aplicar o quadro de princípios e de critérios de silvicultura anichinabé se concentraram no desenvolvimento de indicadores para a proteção das populações animais (critério 3.3), em particular para o alce e o esturjão-de-lago, duas espécies de grande importância cultural. Tal como as observações de Fraser e al. (2006), o acompanhamento das populações de alces enfrentou diversas restrições ligadas à disponibilidade dos dados e à mobilização comunitária no controle das atividades de caça.

O potencial da nossa proposta de silvicultura anichinabé, baseada em cinco princípios e 22 critérios, ainda não foi plenamente explorado como ferramenta de planejamento e avaliação estratégica. Da mesma forma que na maioria das comunidades indígenas do Quebec e do Canadá, Kitcisakik ainda tem dificuldades para elaborar sua visão do ordenamento do território. Neste aspecto, apoiamos o comentário de Leroux (a imprimir): « O povo de Kitcisakik conseguirá estabelecer seus laboratórios de experimentação com sucesso a partir do momento em que os seus dispositivos de controle sobre os recursos territoriais tiverem aumentado. » Entretanto, os trabalhos de Wyatt, Fortier e Hébert (2009) sugerem que diversas formas de envolvimento das comunidades indígenas na silvicultura, e a combinação de várias estratégias, podem ser a chave para um caminho rumo a uma autonomização maior.

\section{EJIGABWINN: A HORA DAS CONVERGÊECIAS}

Os povos indígenas do Canadá estão sujeitos a numerosas consultas quanto à exploração dos recursos naturais presentes nos seus territórios ancestrais. As estratégias de avaliação dos projetos baseadas em critérios e indicadores desenvolvidos localmente podem favorecer a articulação de uma resposta culturalmente adaptada. No Quebec, as tabelas de administração integrada dos recursos e do território, implementadas no contexto da nova gestão florestal, privilegiam essas abordagens avaliativas para apoiar os atores na sua participação do planejamento florestal.

Neste sentido, Kitcisakik já possui as ferramentas para analisar as propostas de ordenamento ou para formular outras opções ancoradas nos valores e aspirações comunitários. O processo de pesquisa apoiou o reforço de competências coletivas e uma forma de aprendizagem social multissetorial à escala regional. Os nossos trabalhos favoreceram também a institucionalização de um departamento responsável pelo ordenamento do território em Kitcisakik e o desenvolvimento de novos projetos florestais empregando vários membros da comunidade. Com base no contexto legislativo e normativo que caracteriza atualmente o ordenamento florestal no Quebec, encontramo-nos na encruzilhada, na qual Ejigabwîn, as pegadas anichinabés, só poderão se inscrever na paisagem cultural de acordo com várias condições. Os princípios de silvicultura indígena desvendados por esta pesquisa podem levar a certa forma de convergência, a qual se inscreve na contemporaneidade, respeitando o caráter identitário da floresta para o povo de Kitcisakik. 


\section{AGRADECIMENTOS}

Este trabalho de pesquisa não teria sido possível sem o envolvimento de toda a comunidade de Kitcisakik. O apoio do Chefe James Papatie e dos chefes, os quais o sucederam (Edmond Brazeau, Adrienne Anicinapeo), foi determinante. $\mathrm{O}$ apoio dos idosos, o entusiasmo dos jovens adultos e a determinação dos nossos assistentes de pesquisa foram elementos essenciais para realizar os nossos trabalhos. A nossa gratidão vai particularmente aos nossos colegas e assistentes de Kitcisakik : Régis Penosway, Robert Penosway, Johanne Papatie, Louisa Papatie e Jacqueline Michel. Yvan Croteau, Claire Dubé, Hugo Asselin foram uns colaboradores preciosos. Agradecemos também Lucie Sauvé, Daniel Kneeshaw, Yves Bergeron e Luc Bouthillier pelo envolvimento nesta pesquisa e Caroline Roger do Serviço das parcerias da UQAM. Agradecemos, por último, os nossos parceiros industriais e governamentais: Michel Sigouin, Geneviève Labrecque, Yvon Pomminville, Pierre Garceau, Claude Lebel, Simon Vézeau, Denis Audette, Mario Poirier e Luc Bernard. Esta pesquisa beneficiou do apoio financeiro do programa de parcerias em silvicultura do CRSNG/CRSH/ Serviço canadense das florestas e da Rede de gestão sustentável das florestas.

\section{BIBLIOGRAFIA}

ADAM, M.C., et D. KNEESHAW, 2008 : « Local level criteria and indicator framework: A tool used to assess aboriginal forest ecosystem values ». Forest Ecology and Management 255 : 2024-2037.

BARDIN, L., 1993 : L’analyse de contenu. PUF, coll. «Psychologue », Paris.

BERKES, F., et I.J. DAVIDSON-HUNT, 2006 : « Biodiversity, traditional management systems and cultural landscapes: examples from the boreal forest of Canada ». International Social Science Journal 58(187) : 35-47.

BERKES, F., et C. FOLKE (dir.), 1998 : Linking social and ecological systems: management practices and social mechanisms for building resilience. Cambridge University Press, Cambridge.

BONFIL BATALLA, G., 1989 : «La teoría del control cultural en el estudio de procesos étnicos ». Arinsana 10 : 5-36.

BOUSQUET, M.-P., 2002 : « Les Algonquins ont-ils toujours besoin des animaux indiens? Réflexions sur le bestiaire contemporain ». Théologiques 10(1): 63-87.

BRUBACHER, D., 1998 : «Aboriginal forestry joint venture: Elements of an assessment framework ». The Forestry Chronicle $74(3): 353-358$.

BUGGEY, S., 1999: Une introductionàl'étude des paysages culturels. Commission des lieux etmonuments historiques du Canada, Parcs Canada, Ottawa.

CAJETE, G., 1994 : Look to the Mountain: An Ecology of Indigenous Education. Kivaki Press, Durango, Colorado. 
au Canada : Bilan national 2005. Ressources naturelles Canada, Service canadien des forêts, Ottawa. $<$ http://www. ccfm.org/francais/coreproducts-criteria_in.asp> (consulté 12 février 2013).

COLLIER, R., G. PARFITT et D. WOOLLAR, 2002 : A voice on the land: An Indigenous peoples' guide to forest certification in Canada. National Aboriginal Forestry Association and Ecotrust, Ottawa.

CONSEIL CRIS-QUÉBEC SUR LA FORESTERIE, 2009 : Entente concernant une nouvelle relation entre le gouvernement du Québec et les Cris du Québec : Bilan de la mise en œuvre des dispositions portant sur la foresterie : 2002-2008. Version abrégée, Québec.

CROTEAU, Y., [à paraître] : « Communications et consultations sur les ressources naturelles : Une occasion d'éloignement et de rapprochement entre les autochtones et les allochtones ». Cahiers du CIERA, Université Laval, Québec.

CUOQ, J.A., 1886 : Lexique de la langue algonquine. J. Chapleau et fils, Montréal.

DAVIDSON-HUNT, I.J., 2003 : « Indigenous lands management, cultural landscapes and Anishinaabe people of Shoal Lake, Northwestern Ontario, Canada ». Environments 31(1) :21-41.

DAVIDSON-HUNT, I.J., et F. BERKES, 2003 : « Learning as you journey: Anishinaabe Perception of Socialecological Environments and Adaptive Learning ». Ecology and Society (Conservation Ecology) 8(1) : 1-21. <http:// www.consecol.org/vol8/iss1/art5> (consulté le 26 juin 2007).

DAVIDSON-HUNT, I.J., et D. O’FLAHERTY, 2007 : « Researchers, Aboriginal peoples and place-based learning communities. Society and Natural Resources $20: 291-305$.

DRAPEAU, L., 1999 : Dictionnaire Montagnais-Français. Presses de l’Université du Québec, Sainte-Foy.

DUMONT, M., et M. PAPATIE-DUMONT, 1985 : Lexique algonquin-français. Conseil de bande du Lac Simon, Québec.

FSC (Forest Stewardship Council), 2012:FSC guidelines for the implementation of the right to free, prior and informed consent (FPIC), 1re version. $<$ https://www.ic.fsc.org/technical-updates.325.254.htm> (consulté le 25 mai 2012).

FRASER, E.D.G., et al., 2006 : « Bottom up and top down : Analysis of participatory processes for sustainability indicator identification as a pathway to community empowerment and sustainable environmental management $»$. Journal of Environmental Management 78(2): 114-127.

GAYFORD, C., 2003 : «Participatory methods and reflective practice applied to research in education for sustainability ». Canadian Journal of Environmental Education 8 : 129-142.

GERMAIN, R., 2012 : Acceptabilité sociale de l'aménagement écosystémique : le point de vue des Algonquins de Pikogan. Mémoire de maîtrise, département de biologie, Université du Québec en Abitibi-Témiscamingue. <http:// 
www.archipel.uqam.ca/5246/1/M12667.pdf> (consulté le 7 mai 2013).

GERMAIN, R., et H. ASSELIN, 2011 : Zonage du potentiel d'intérêt autochtone : un nouvel outil d'aide à la décision. Note de recherche n ${ }^{\circ}$ 71, Réseau de gestion durable des forêts, Université de l’Alberta, Edmonton.

GILL, S., 1990 : « Mother Earth: An American myth», in J.A. Clifton (dir.), The Invented Indian: Cultural fictions and government policies : 129-143. Transaction Publishers, Londres.

GLADU, J.P., et C. WATKINSON, 2004 : Measuring Sustainable Forest Management: A compilation of Aboriginal indicators. A Report Prepared for the Canadian Model Forest Network. Aboriginal Strategy Group.

GOUVERNEMENT DU QUÉBEC, 2002 : Entente concernant une nouvelle relation entre le gouvernement du Québec et les Cris du Québec. Québec. <http:/www.autochtones.gouv.qc.ca/relations_autochtones/ententes/cris/ entente_cris_20020207.pdf> (consultéle 6 mai 2013).

GTICA(Groupe de travail interministériel sur la consultation des autochtones), 2008 : Guide intérimaire en matière de consultation des communautés autochtones. Gouvernement du Québec, Secrétariat aux affaires autochtones, Québec. $<$ http://www.autochtones.gouv.qc.ca/publications_documentation/publications/guide_inter_2008.pdf> (consulté le 6 mai 2013).

IDDPNQL (Institut de développement durable des Premières Nations du Québec et du Labrador), 2005 : Protocole de consultation des Premières Nations du Québec et du Labrador. Assemblée des Premières Nations du Québec et du Labrador. Wendake. <http://www.iddpnql.ca> (consulté le 24 janvier 2013).

—, 2013: «Atelier sur le transfert des certificats FSC au gouvernement du Québec, les 22 et 23 janvier 2013 ». Compte rendu des présentations et des discussions. IDDPNQL, Wendake.

JODELET, D. (dir.), 2003 : Les représentations sociales. 7e édition. Presses universitaires de France, Paris.

KARJALA, M.K., et S.M. DEWHURST, 2003 : « Including Aboriginal issues in forest planning: A Case study in Central Interior British Colombia, Canada ». Landscape and Urban Planning 64(1-2) : 1-17.

KARJALA, M.K., E. SHERRY et S.M. DEWHURST, 2004 : «Criteria and indicators for sustainable forest planning: a Framework for recording Aboriginal resource and social values ». Forest Policy and Economics 6(2) : 95-110.

KRECH, S., 1999: The Ecological Indian: Myth and History. Norton and Company, New York.

LAROUCHE, M., 2008 : La modélisation de scénarios d'aménagement forestier à l'échelle du paysage : un outil d'aide à la décision en foresterie autochtone. Mémoire de maîtrise, département des sciences biologiques, Université du Québec à Montréal. <http://www.archipel.uqam.ca/1361/1/M10338.pdf> (consulté le 6 mai 2013).

LEBUIS, V., et G. KING-RUEL, 2010 : « Le consentement libre, préalable et informé : une norme internationale en émergence pour la protection des populations locales autochtones ». Recherches amérindiennes au Québec 40(3): 
$85-99$.

LEMOINE, G., 1909 : Dictionnaire français-algonquin. G. Delisle, Chicoutimi.

LEROUX, J., 1992 : « Le tambour d'Edmond ». Recherches amérindiennes au Québec 22(2-3) : 30-43.

—, 2003 : Cosmologie, mythologie et récit historique dans la tradition orale des Algonquins de Kitcisakik. Thèse de doctorat, département d'anthropologie, Université de Montréal.

—, [sous presse] : «Aki, la terre algonquine et sa forêt meurtrie », in É. Le Roy (dir.), La Terre et l'homme. Espaces et ressources convoités. Karthala, Paris.

LEROUX, J., R. CHAMBERLAND, E. BRAZEAU et C. DUBÉ, 2004 : Au pays des peaux de chagrin. Les Presses de l’Université Laval, Québec.

LÉVESQUE, C., C. MONTPETIT et S. VINCENT, 1997: Vers une gestion intégrée et durable des activités forestières en Eeyou Astchee : L'élaboration d'un corpus de critères et d'indicateurs d'ordre culturel, social et économique. Institut national de recherche scientifique, Montréal.

MARTON, F., 1994 : «Phenomenography », in T. Husén et T.N. Postlethwaite (dir.), The International Encyclopaedia of Education, vol. 8 : 4424-4429. Pergamon, Oxford.

MERRIAM, S.B., 1998 : Qualitative research and case study applications in education. Jossey-Bass, San Francisco.

NATCHER, D.C., 2006 : « L'économie forestière de la nation crie de Little Red River. Priorisation des modes de production ». Recherches amérindiennes au Québec 36(2-3) : 71-78.

—, 2008 : Seeing beyond the trees: The Social Dimensions of Aboriginal forest management. Captus Press Inc., Concord, Ontario.

NATCHER,D.C., etC.G.HICKEY,2002: «Putting the community backintocommunity-basedresourcemanagement: A criteria and indicators approach to sustainability ». Human Organization 61(4) : 350-363.

ONU (Organisation des Nations unies), 2007 : Déclaration des Nations unies sur les droits des peuples autochtones. Doc. Off. AGNU, 61e session, Annexe, point 68, Doc. NU A/RES/61/295. <http://www.un.org/esa/socdev/unpfii/ documents/DRIPS_fr.pdf $>$ (consulté le 7 mai 2013).

ORELLANA, I., 2005 : «L'émergence de la communauté d'apprentissage ou l'acte de recréer des relations dialogiques et dialectiques de transformation du rapport au milieu de vie », in L. Sauvé, I. Orellana et É. van Steenberghe (dir.), Éducation et environnement : Un croisement de savoirs : 67-83. Actes du colloque “Le croisement des savoirs au cœur des recherches en éducation relative à l'environnement" présenté dans le cadre du 72e Congrès de l'ACFAS, Montréal.

PARSONS, R. et G. PREST, 2003 : «Aboriginal forestry in Canada ». The Forestry Chronicle 79(4) : 779-784. 
POIRIER, S., 2000 : «Contemporanéités autochtones, territoires et (post)colonialisme ». Anthropologie et Sociétés 24(1): 137-153.

PROGRAMME CANADIEN DES FORÊTS MODĖLES, 2000 : Guide d'utilisation des indicateurs locaux de l'aménagement durable des forêts : Expériences du Réseau canadien de forêts modèles. Ressources naturelles Canada, Service canadien des forêts, Ottawa.

RIOJA BALLIVIAN, G., 2005 : « Antropología de frontera: Investigación acción en la región trinacional MAP ». AIBR. Revista de Antropología Iberoamericana 43, Madrid. <http://www.dialnet.unirioha.es/servlet/ articulo?codigo $=1299603>$ (consulté le 7 mai 2013).

ROBOTTOM, I., et L. SAUVÉ 2003 : «Reflecting on Participatory Research in Environment Education: Some Issues for Methodology ». Canadian Journal of Environmental Education 8(1) : 111-128.

SAINT-ARNAUD, M., 2009 : Contribution à la définition d'une foresterie autochtone : le cas des Anicinapek de Kitcisakik. Thèse de doctorat. Institut des sciences de l'environnement, Université du Québec à Montréal. $<$ http:// www.archipel.uqam.ca/2038/1/D1783.pdf $>$ (consulté le 5 juin 2013).

SAINT-ARNAUD, M., H. ASSELIN, C. DUBÉ, Y. CROTEAU et C. PAPATIE, 2009 : « Developing criteria and indicators for Aboriginal forestry: Mutual learning through collaborative research», in M. Stevenson et D. Natcher(dir.), Changing the culture of forestry in Canada: Building effective institutions for aboriginal engagement in sustainable forest management : 85-105. CCI Press et Réseau de gestion durable de forêts, Edmonton.

SAINT-ARNAUD, M., L. SAUVÉ et D. KNEESHAW, 2005 : «Forêt identitaire, forêt partagée : Trajectoire d’une recherche participative chez les Anicinapek de Kitcisakik (Québec, Canada)». VertigO 6(2) : 1-12. <http://www. vertigo.revues.org/4431> (consulté le 7 mai 2013).

SAUVÉ, L., 1997 : Pour une éducation relative à l'environnement. Guérin, Montréal.

—, 2005 : «Repères pour la recherche en éducation relative à l'environnement », in L. Sauvé, I. Orellana et É. van Steenberghe (dir), Éducation et environnement : Un croisement de savoirs : 27-49. Actes du colloque « Le croisement des savoirs au cœur des recherches en éducation relative à l'environnement », présenté dans le cadre du 72e Congrès de l'ACFAS, Montréal.

SAUVÉ, L., et C. GARNIER, 2000 : « Une phénoménographie de l'environnement : réflexions théoriques et méthodologiques sur l'analyse des représentations sociales », in C. Garnier et M.-L. Rouquette, Représentations sociales et éducation : 211-234. Éditions Nouvelles, Montréal.

SAUVÉ, L., et al., 2005 : « Regards croisés sur une "éducation relative à l'environnement" en milieu autochtone ». Recherches amérindiennes au Québec 35(3) : 85-94. 
SAVARD, R., 2004 : La forêt vive : Récits fondateurs du peuple innu. Boréal, Montréal.

SHERRY, E., et al., 2005 : « Local-level criteria and indicators: An Aboriginal perspective on sustainable forest management ». Forestry 78(5): 513-539.

SMITH, L.T., 1999 : Decolonizing methodologies: Research and indigenous peoples. Zed Books, Londres.

STEVENSON, M.G., et P. PERREAULT, 2008 : Capacity for what? Capacity for whom? Aboriginal capacity in Canada's forest sector. Réseau de gestion durable des forêts, Université de l'Alberta, Edmonton.

TANNER, A., 1979 : Bringing home animals: Religious ideology and mode of production of the Mistassini Cree hunters. St. Martin's Press, New York.

—, 2007 : « The Nature of Quebec Cree Animist Practices and Beliefs », in F.B. Laugrand et J.G. Oosten (dir), La nature des esprits dans les cosmologies autochtones/Nature of Spirits in Aboriginal Cosmologies : 133-150. Les Presses de l'Université Laval, Québec.

TEITELBAUM, S., et S. WYATT, 2012 : «Is forest certification delivering on First Nation issues ? The effectiveness of the FSC standard in advancing First Nations' rights in the boreal forest of Ontario and Quebec, Canada ». Forest Policy and Economics 27 :23-33.

UNESCO, 2013 : Centre du patrimoine mondial - Paysage culturel. Histoire et terminologie. <http://whc.unesco.org/ fr/paysageculturel $>$ (consulté le ler mars 2013).

UPRETY, Y., H. ASSELIN et Y. BERGERON, 2013 : «Cultural importance of White Pine (Pinus strobus L.) to the Kitcisakik Algonquin community of western Quebec, Canada». Canadian Journal of Forest Research 43 : 544-551.

VINCENT, O. (dir.), 1995 : Histoire de l'Abitibi-Témiscamingue. Institut québécois de recherche sur la culture, Presses de l'Université Laval, Québec.

WAPIKONI MOBILE, s.d. : Wapikoni mobile : Cinéma des Premières Nations. <http://www.wapikoni.tv> (consulté le 15 février 2013).

WASWANIPI CREE MODEL FOREST, 2007 : Ndoho Istchee: An Innovative approach to Aboriginal participation in forest management planning. The Cree First Nation of Waswanipi, Québec.

WYATT, S., 2004 : « Co-existence of Atikamekw and Industrial Forestry Paradigms: Occupation and Management of Forestlands in the St-Maurice River Basin, Québec ». Thèse de doctorat, Faculté de foresterie et de géomatique, Université Laval, Québec. 
foresterie au Nitaskinan ». Recherches amérindiennes au Québec 36(2-3) : 9-18.

—, 2008 : «First Nations, Forest Lands, and “Aboriginal Forestry” in Canada: From Exclusion to Comanagement and Beyond ». Canadian Journal of Forest Research 38(2) : 171-180.

WYATT, S., J.F. FORTIER et M. HÉBERT, 2009 : « Multiple forms of engagement: Classifying Aboriginal roles in contemporary Canadian forestry ", in M. Stevenson et D. Natcher (dir.), Changing the culture of forestry in Canada: Building effective institutions for Aboriginal engagement in sustainable forest management : 163-180. CCI Press et Réseau de gestion durable de forêts, Université de l'Alberta, Edmonton.

\section{JURISPRUDÊNCIA}

Nation Haïda c. Colombie-Britannique (Ministère des Forêts) [2004] 3 R.C.S. 511.

Première Nation Tlingit de Taku River c. Colombie-Britannique (Directeur de l'évaluation de projets) [2004] 3 R.C.S. 550.

Loi sur l'aménagement durable du territoire forestier. L.R.Q. c. A-18.1.

\section{NOTAS}

1. Os Algonquinos fazem parte da grande família etnolinguistica dos Algonquianos, a qual inclui também os Abenakis, os Attikamekw, os Crees, os Innus, os Malécites, os Micmacs e os Naskapis. Os Algonquinos de Kitcisakik se referem a eles na sua língua com a palavra Anicinape ou Anicinabe, no singular, e Anicinapek, no plural, a qual significa « homens verdadeiros ». Entretanto, a política editorial da revista se conforma com o Office quebequense da língua francesa, o qual recomenda mais o uso de « anichinabé(s) » em francês, término que conservamos para a versão do presente artigo em português.

2. «Kitcisakik» é a palavra algonquina que significa « na grande desembocadura» para se referir ao Grand lac Victoria, um alargamento do rio dos Outaouais (Quebec), às margens do qual se encontra o local de encontro de verão da comunidade. Este local foi ocupado por um dos primeiros comptoirs d'échange da Companhia da Baía de Hudson estabelecida em Abitibi-Témiscamingue durante a primeira metade do século XVIII (Leroux e al. 2004).

3. A Lei sobre o ordenamento sustentável dos territórios florestais define a « atividade de ordenamento florestal» sendo uma atividade « vinculada ao corte e à colheita da madeira, à cultura e à exploração das florestas de bordo, à construção, à melhoria, à manutenção e ao encerramento de infraestruturas, à execução de tratamentos silvícolas, incluindo o reflorestamento e o uso do fogo assim como o controle dos incêndios, dos insetos-pragas, das doenças criptogâmicas e da vegetação concorrente, tal como qualquer outra atividade de natureza similar tendo um efeito tangível nos recursos do ambiente florestal ». Usaremos no mesmo sentido a palavra « silvicultura », traduzida do francês do Quebec « foresterie». 
4. As empresas Domtar (EACOM Timber Corporation), Tembec, AbitibiBowater (Produits forestiers Résolu), Louisiana-Pacifique, Industries Norbord, Bois Oméga, Commonwealth Plywood e Cédex participaram desta parceria de pesquisa.

5. Esta parceria incluía um conjunto de desafios éticos e estratégicos que analisamos detalhadamente conforme ao paradigma crítico ao qual aderimos (Robottom e Sauvé 2003; Saint-Arnaud e al. 2005; Saint-Arnaud 2009). Apresentavam-se os desafios relativos ao controle do desenvolvimento da pesquisa, ao compartilhamento da informação, ao significado simbólico de tal associação comunidade-indústria-universidade. Mas ao finalizar os nossos trabalhos, fomos capazes de afirmar que esta associação de pesquisa beneficiou todos os atores.

6. Segundo a Lei, « Ordenamento Ecossistêmico »: um ordenamento que consiste em assegurar a manutenção da biodiversidade e a viabilidade dos ecossistemas diminuindo as diferenças entre a floresta humanizada e a floresta natural.

7. A certificação florestal é um sistema voluntário de avaliação do desempenho das organizações quanto ao ordenamento florestal sustentável. De acordo com um conjunto de critérios e indicadores, os componentes sociais, do meio ambiente e econômicos do ordenamento florestal são avaliados por ouvintes independentes. A conformidade com esses critérios permite vender produtos florestais que revestem o logo do sistema de certificação. No Canadá, três sistemas de certificação são usados: o CSA(Canadian Standard Association), o SFI (Sustainable Forestry Initiative) e o FSC (Forest Stewardship Council). Esse último chega ao topo das superficies certificadas.

8. Os dicionários algonquinos antigos não fazem nenhuma referência à noção de « Mãe-Terra ». Tratar-se-ia de uma representação moderna, introduzida no discurso dos indígenas sobre o meio ambiente (Gill 1990 ; Krech 1999) a partir do século XX para se referir à sua representação da terra nutridora. Ela dá vida e eles a associam à sua cultura tradicional.

9. Ver os curtas-metragens realizados por alguns jovens de Kitcisakik no âmbito do projeto Wapikoni (s.d.).

\section{FIGURAS E FOTOS}

Figura 1

Localização do território de Kitcisakik

Figura 2

O sistema representacional da floresta para os Anichinabés de Kitcisakik 
Figura 3

O sistema representacional da silvicultura para os Anichinabés de Kitcisakik

Figura 4

Princípios e critérios de silvicultura indígena para Kitcisakik

Foto 1

O lugar de encontro de verão de Kitcisakik às margens do Grand lac Victoria

(Foto de Régis Penosway, 2004)

Foto 2

Charlie Papatie e Marie Saint-Arnaud visitando um canteiro de cortes de árvores no território de Kitcisakik

(Foto de Régis Penosway, 2004)

Foto 3

Atelier de validação do quadro de silvicultura anichinabé

(Foto de Marie Saint-Arnaud, 2006) 